\title{
The Importance of the Strategy Governance for the Preservation of the Performance of the Teams
}

\author{
Soumaya Dlimi \\ Faculty of Economic and Social Legal Sciences, University Hassan II, Casablanca, Morocco
}

\begin{abstract}
The performance of the teams stays one of the priorities of every organization. In an environment « disrupted »under pressure, and hyper competitiveness , the Moroccan companies at present , are submitted to several competitive pressures which require from them more flexibility, reactivity and adaptability. The objective is to discover how the strategy governance can lead the teams towards a performance to the continuous one. The methodology is as follows: The ground of study is the Moroccan SME (Small and medium-sized enterprise).The adopted epistemological posture is the interpretative posture, in a hypothetical-deductive approach (within the framework of theoretical and empirical study). The study which we plan to present in this article is the partial result of our research project in Sciences of Management. We began fortunately the empirical part (visit of 136 companies). Then, we shall try in this article to discover, the importance of strategy governance for a better performance of the team. So, in this sense, as a conclusion, if the Moroccan SME has for objective the adaptation for a preservation of their stability and an effective presence in the Moroccan economy, it resorts only the implementation of good governance able to leading their team toward the durability of the action.
\end{abstract}

Key Words: Governance, performance, SME, disrupted environment, hyper competitiveness, team, objectives

\section{Introduction}

The installation of tools mental improved able to help in the restoration of a more powerful organizational architecture remains the pillar of building work, when we speak about effectiveness and relevance, or performance of the teams, of any authority which claim to control in a world without top nor center.

In a world of turbulence that we can call" disturbed environment", the approach governance is emerging in which several concepts will play a central role.

The object of this article is to show how certain concepts conform the problematic governance, and especially, to try to find which governance for a better performance of the team? Here what will allow us finally to speculate on what enables us to ensure the sustainability of the action in burst universe?

Why the choice of this set of themes? Simply because the performance of the teams remains one of the priorities of each organization. In an environment "disturbed" under pressure, and hyper competitiveness, the Moroccan companies at present, are subjected to several competing pressures which require from them more flexibility, reactivity and adaptability.

In this direction, if Moroccan SME (Small and medium-sized enterprise) has for objective the adaptation for a preservation of its stability and an effective presence in the Moroccan economy, it resorts only the installation of a good governance able to carry out its teams towards the durability of the action.

The key would certainly be to know the stakeholders, to interest them in partnerships, to draw alliances on the basis of principle promising an effective collaboration, without omitting the implementation of the mechanisms which are going to converge without a shadow of doubt actions inspired by divergent objectives, and certainly, to insure the minimum of adhesion the standards, so that each partner is carried to honor his commitments.

To work to think well the governance in search of the performance of the team remains complex. Why? Simply because to examine the configuration of the participants whom it tries to mobilize, to know the powers, rights, needs, obligations, etc of each actor, will have to lead us to better understanding why and how they coordinate their activities for a coherence of the collective action.

Corresponding author: Soumaya Dlimi, PhD, Faculty of Economic and Social Legal Sciences, University Hassan II, Casablanca, Morocco, Email: soumayadlimi@gmail.com

This article is distributed under the terms of the Creative Commons Attribution License, which permits unrestricted use and redistribution provided that the original author and source are credited. 
The study which we plan to present in this article is the partial result of our research project in Sciences of Management. We fortunately started the empirical part (visit of 136 Moroccan companies). Consequently, we try in this article to discover, how the governance can have a narrow relation with the performance of the teams, and especially, which governance for a better performance of the teams?

\section{Problem}

This subject of research is interested in organizational problems in direct link with the performance of the teams in SME in Morocco: "Which governance for a better performance of the teams"?

The purpose of our research is, initially, to identify, study and analyze the problematic governance in Moroccan SME, which succeeded in maintaining their market shares in spite of the world competition and the crisis. Secondly, this search aims to explain the strategic choices of these SME, through the practice of the good governance, their leaders, all these brief replies will make it possible to understand which governance allows the durability and the sustainability of the action, the result, and thus the performance of the teams.

\section{Governance: Why and which interest for a team in search of the performance?}

To speak about "governance", it is to connote the coordination of all the grateful partners if we really wish to reach a good performance. It became clear that nobody can assume the role of host any more.

Admitting that the team leader who aspires to lead is team towards a better performance, tries to be made the catalyst, he could thus become "a handyman" of coordination more at least effective of all the strengths going to all the directions to assure the performance of his teams.
The question which is obviously imperative in front of us it is: Why within the framework of a "disturbed environment" where lives and survive the Moroccans SME, to speak about governance? What is the interest for a team to think deeply of this practice?

So, the absence of the practice of good governance can be one of the factors which prevented or slows down the performance of the non powerful teams. The governance is thus within the framework organizational at the same time a manner of seeing of seeing and framework of analysis.

The concept of problematic governance has a great strategic vagueness. Thus, the hypothesis that we released from our research work is that it there was in the steering of the organizations: Great G" Government", more coercive, authoritarian, hierarchical and centralized; and then modes of steering young $\mathrm{g}$, which are more horizontal, pluralistic, participative, and experimentalists.

Jean-Pierre GAUDIN pointed out that the word governance exists since the $13^{\text {th }}$ century, and nevertheless, he reappeared at the $21^{\text {st }}$ century, for new needs. Nobody can autocratically impose any more his steering in one wave of organization where the resource, the power and the information are distributed between several hands.

Today within the framework of our article, we shall try to clear up how the good governance can be a performance lever of the teams in the Moroccan SME.

Why had we chosen as ground of study the Moroccan SME? We justify our choice by the importance of SME in the developing countries, which is confirmed on the statistical plan. They represent $90 \%$ companies in the majority of developing countries (OCDE, 2002, 2006 and 2007; Douing Business, 2014). In Morocco SME creates 50\% employment, contributes of $2 \%^{\circ}$ to the GDP ( Gross Domestic Product), 30\% with exports and $40 \%$ with the production ( ANPME, 2013). 


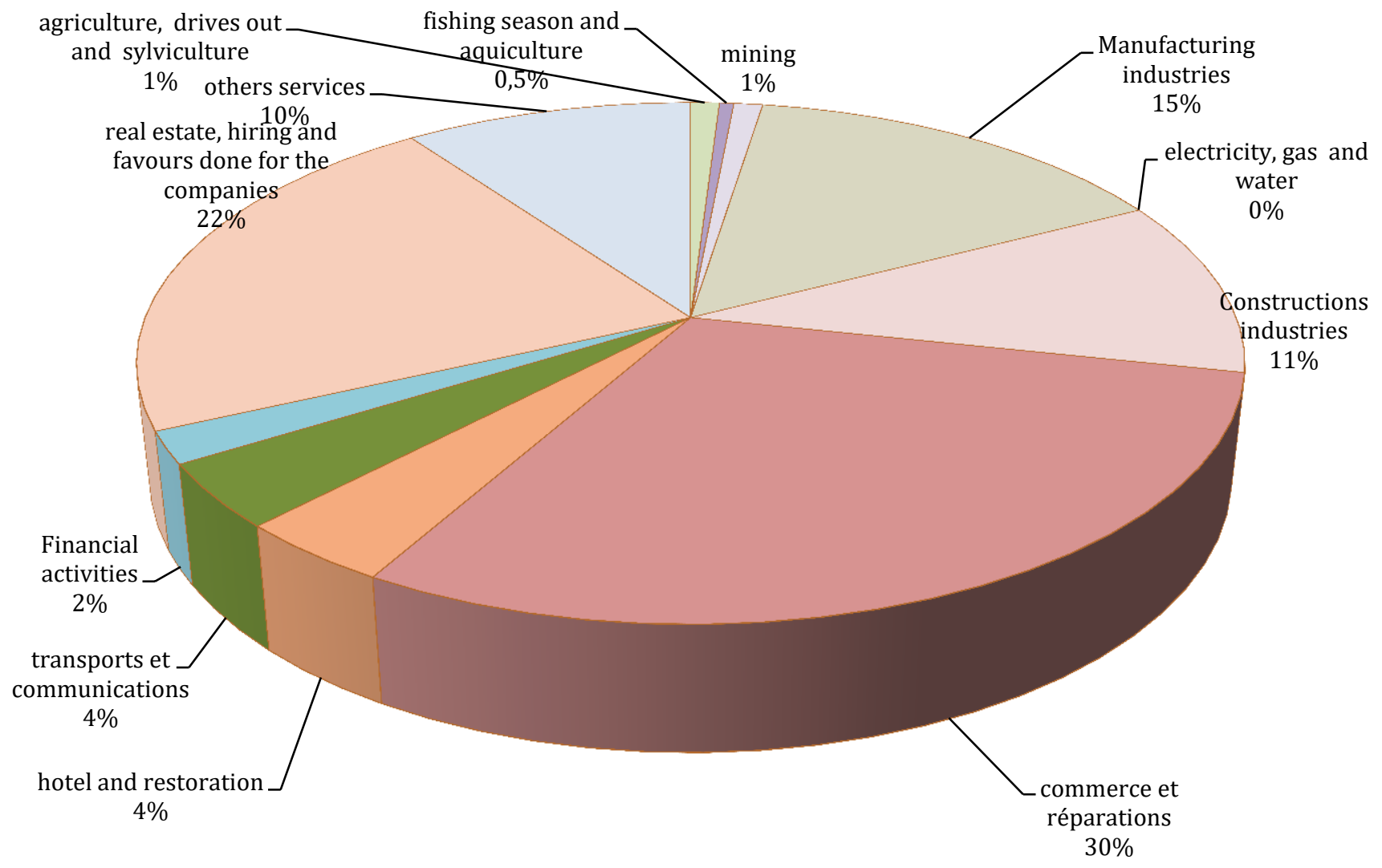

Figure 1: Distribution of Moroccan SME by economic branches of activity

In spite of their part of $15 \%$ in the population of Moroccan SME, manufacturing industries generate the greatest added-value with a contribution of $37 \%$. They are followed by the activities of trade and repairs $19^{\circ}$ and of the real estate and the corporate services $13 \%$.

In terms of number of companies, the weight of the SME represents $98^{\circ}$ of the whole national productive fabric. The share of SME is of more than $9 \%^{\circ}$ in all business sectors except that of the production and electricity supply, the gas and the water, where this participation is only of $50 \%$.

However, SME remains vulnerable considering the multiple constraints which she sees forced to face, from where the continuous combat of the leaders to maintain the performance of their teams. The interest thus to speak about governance within the framework of Moroccan SME is to consider that the governance is at the same time a way of seeing, a framework of analysis and a language of definition and solution of problem, a device of clinical examination to go to the source of the bad performance. It is indeed about a mental equipment for every organizational designer, to become a social architect.

To answer thus our quoted question higher: why governance and which interest for the performance of the teams in Moroccan SME? We shall assert simply that it is about necessity today!
The déconcertation raises serious problems, and the latter are often badly diagnosed considering that they are often approached by functional prospects reducing-finances, human resources, etc.

The word governance reminds to all those who claim to be in authority which all our SME do not have any more as formerly, absolute master on board. The direction is not the fact of a person, a pilot, but circuits and complex surrounding, little as it is the case for the autopilot of a plane.

Therefore, the governance it is these circuits and networks that connect shareholders, members, citizens, workers, suppliers, customers, groups of interest, media, elected representatives, state employees and statutory authorities of the various levels of government, and which leads the various actors to coordinate their activities so as to ensure a real dynamic performance.

However, the pilot "as we had called higher and we allowed ourselves the allegory- have a program, but often nobody can be held responsible for a fault because several speakers took part in decision making. And there let us admit it, exists indeed the pathology of governance, which can carry out toward a miserable performance.

The "good governance" aims at ensuring that information circulates well, that networks and circuits are well nets of jamming, that each agent knows its rights and responsibilities. 
It remains all the same very difficult to make understand to those who take themselves for potentates that nobody handles, that nobody can alone take control of the device: That it is necessary to collaborate for a better performance of all the team! A cunning mixture of mechanisms of different kinds will be needed rather: pressure, reciprocity and much more, and to muddle them to orchestrate effectively the good exploitation of the knowledge, and there we position us very far from the taylorian caporalism.

We imagine a triangle where coexists the hierarchy, the co-operation and the exchange, each one at the top of a peak, and in the middle of the triangle a relational mess, where the mechanisms are mixed. We can see thus more coexisting various mixtures of trade, hierarchical and cooperative relations in several compartments within the same organization, and to see these mixtures evolving according to the changes of gives (Thomas, 2000).

Also, if the hierarchy, the co-operation and responsible autonomy become entangled, we will attend a malleable system of production and treatment of knowledge, and thus, better performance of the teams.

If we wish to arrive thus at a better performance, best would be to return to the problem governance, which tries to define the organization by its informative DNA, by the nature of the exchanged messages, and by the contribution of the organizational capital to the production of knowledge and skills (Saint-Onge \& Armstong, 2004) .

We arrive if we follow the advance that we trace since the first lines of our article, to the following fact: we are in front of a key dimension of the organizational design, because if we try to modify the informational screen, so as to transform the incentives and motivations in the direction of an accelerated training, source of added-value and innovation. We are on the other hand conscious that the adaptation and the training often borrow unforeseeable ways, and can take undesirable ways.

We think when we underline the importance of "design" concept for the processes complexes and in evolution within the framework of every organization, and who cannot build themselves simply. It is a question of throwing (launching) a process of intelligent exploration, a "survey" guided by an escaped appreciation of places based on the past experience, to produce (in Donald's A. sense, and Schôn, 1990) has selective representation of the year unfamiliar that situation sets been worth for the system transformation. It frames the problem of the problematic situation and thereby sets direction in which solutions dregs and proempty has plan for exploring them.

In fact the organizational design is a conversation with the situation which leads to the invention of structures which reveal conflicts and dilemma in the system of appreciation. It can be explained by the divergences and the differences of the reference frames of the participants.

The approach governance presents through a long review of literature the organization as a set of temporary and escaped armistices between values and context, and the organizational analysis which wants to establish a useful intervention rests fundamentally at first, as asserts it Bent Flyvgerg( 2001), on the answers to four questions: where do we go? Are these planned developments desirable? What can we make? And who loses and which wins by which mechanisms of sliding of power?

Such an approach bases itself on a lot of scattered piece of information, knowledge of the private individual, the inductive wisdom, but the objective is to answer the key issue of our article: what can we make for a better performance of the teams?

\section{The Durability and the Sustainability of the Action: Which Governance for a Performance of the Teams}

\section{Concept of performance}

The concept of performance is defined compared to the triptych "Objectives, Means, Results". In other words if a company wants to reach the performance, it imperatively must, to respect this "triptype" and to realize coherence between its components

The relations between these elements are:

- The relevance enters the means and the objectives

- The effectiveness enters the results and the objectives

- Efficiency enters the results and the means.

"The performance "is defined according to A. Bourgignon (1996), starting from an etymological and semantic analysis, in three different directions: $1 /$ the performance is a success. The performance does not exist in oneself; it is function of the representations of the success, variable according to the companies and the actors.

$2 /$ the performance is result of the action, evaluation ex post got result

$3 /$ the performance is action, being read as the process which concludes the successfully"

Under these conditions, "the performance does not miss a reference mark on which to rest: economic (profitability, productivity), legal (legal conformity, solvency) organizational (competence, coherence, efficiency) or social (synergy, implication, satisfaction of the employees, development of the potentials, quality of life to work)" (Louart, 1996).

Our research project will focus on the durability of the action, the result, leading to the success to the continuous. We can for example "to restrict the performance of human resources to social stakes 
either to act on such stakes by adapting them to the strategy (according to a logic of dependent adjustment ) or by considering that the people are active resources which, by conflict or cooperation, intervene on the strategic choices" (Louart, 1996).

\section{Principles and forms of governance}

If we understand better some principles of organizational architecture, we shall observe better results as regards the governance. Some simple principles but quite as imposing and robust remain to be revealed:

The principle of multistability: it suggests that the best way of stabilizing a differentiated system is to segment it in subsystems, and to allow that of the subsystems ready to make it deal with the adjustments necessary when it there are shock or disturbance. That makes it possible to arrive at less cost, because the system is neither obliged nor forced to change as a whole.

The principle of competition: why? Because it is the principle of anti-monopoly. The competition is source of innovation, learning and effectiveness and thus efficiency of the teams. The principle of democracy: it is to ensure the maximum of shared knowledge, the maximum of participation, and thus it is indeed about a commitment to honor with commitments made, openly and publicly.

The principle of democracy: it is to ensure the maximum of shared knowledge, the maximum of participation, and thus it is indeed about a commitment to honor with the made commitments, with considering and with know of all.

The principle of the truth: we speak here about truth of the prices and the costs, which remains a simple principle of transparency and clearness. It makes it possible to any actor to make the wisest decisions.

The principle of subsidiary: this principle favors the procedures which postpone at the level low and most local possible decision making, and to agree to off-set the decision on a higher level only if it is essential.

\section{Governance, collaboration and durable perfor- mance}

The concept of collaboration remains powerful but ambiguous: it allows the mobilization of the network (the network is a way of organizing the production and the division of knowledge, and collaboration, (Nadine Massard, 1997), but it can be also spread in synchrony or swan in the crowd which, by contagion, can become dangerous.

Admittedly it can be spontaneous, but approach the concept with the G.H Mead (George H.Mead, 1963), for which the communication is all that interrelated the control of the members of the company, the problem of coordination and collabo- ration becomes the challenge to set up the requirements so that, of the interactions, bind the practices and conventions between individuals who take part in an interaction, so that emergent of stable and regular connections, and thus a durable and perennial performance.

Mead (1963) asserts in this sense that the relational design of the reality makes it possible to understand how collaboration emerges basically from the obligation to adjust itself and to adapt to the actions of the others. This adaptive work allows a system of prospection (inquiring systems), because there is presence of interaction and relations which generate practices and conventions.

\section{Governance, reflexivity and sustainable perfor- mance}

Reflexivity generates in the course of experience a redefinition on the problems. This process does not only aim at reflecting on the processes of homing, of self-regulation which emerges, but also on the process of auto-creation which the organization is in the moment of living (Gilles, 2005).

The steering will not come directly from the leader any time and in any event, but we can more speak about pilot (driver) or of "steward ship" (Paul Skidmore, on 2004). It will rather be a plural reaction to the environment, the effort of each to mobilize all the knowledge and the available energies, the mixture of question of the zones of comfort and subversion but at the same time empouvoirement, manners to encourage the action (share) of the largest number. And from there will raise spontaneously a will, to return the long- lasting, stable action, and thus, a preservation of the performance of teams.

Parr and al (2002) underline that we need some processes to arrive at the durability of the action within the framework of good governance: an effort to draw the attention on the gap between the current reality and what would be desirable, so as to make recognize by all the necessity of exploring the possible actions. Besides, the double work of mobilization (definition of the critical stakes, the information able to inspire and to motivate most rand counts people of the different networks (and of supports (media) in the collaboration (organized by working platforms together, development of new relations, and encouragement in the exploration of new avenues) And finally, a continuous work of renewal of the processes to keep in a optimum way capacity to learn and explore challenges always changing.

There will be the key of preservation of the performance, since it is necessary to learn, to restructure. It is there the crucial challenge of the collaborative and reflexive governance there. According to Gilles (2009), she will allow certainly the integration of the knowledge and the learning 
(apprenticeship) in the action; capacity to prospect the effects of long-term systems; adaptation of the strategies and the structures; participative and interactive definition of the big directions (managements); and interactive development of the strategies.

It is important to specify the utility of the phase of adaptation in the management of the change (Garfield, on 1986), who is more difficult." Remain a student for life, expect the success, build up to itself alternatives of future, and update its project"

These elements will allow optimizing the known, to widen the borders of the new, and especially, in phase of competitiveness, to lead (drive) the change, and to maintain the performance. The shadow of doubt, an engine of sustainable performance. But how in this context maintain again and again the performance of the teams? Thus the challenge to maintain durably the performance of the teams is to reveal what allows the people to want of fights "for" or against", to channel their energy so that, in the action, they learn on them and so, they find some pleasure to share their talents, to cooperate, to become more supple, more reactive and so that they use this available energy to anticipate the change, to remain all the time successful.

With this intention, the best way for the manager is to ask himself the good questions before all actions: how the objectives are fixed, negotiated? Up to what point are they accepted by the members of the team? Do they consider themselves little informed, little consulted?

Do they doubt the realistic character? Do the competitive strategies installed put under stress the team?

Do they think not to arrange sufficient ways to reach them? are they in opposition with their value system?

How is this "not acceptance" expressed? Does there exist a control of the results of the team and one of the variation? How and by which it is made? For what is used it? How this control as regards relations is lived?

How each member of the team found is in the total performances? Does the team seek to know the needs and the motivations of her members for better taking account of it "and helping them in their development? The team has it a approach "marketing with respect to her interlocutors in the company: Does she take account of their needs, their requests ? or she works centered on herself and her own concerns?

In what do the characteristics of this environment of team- under competing pressure- open on outside and with the change or do they fold up it on itself and do they fix it on the past?

Is one often encumbered, overflowed, saturated by the activities? How the team organized is? How and by which the team work it is envisaged? Distributed? Coordinated? Controlled?

Are the conflicts treated by official channels or within the team?

Patrick Audebert-Lasrochas and team clarifies in "the Intelligent teams" ED of organization, 1999) that the standards and the rules of team game can in situation of competitiveness, o exploit favorably or the reverse the performance of the team. These standards (the values, the practices, modes of behaviors, the language) will have to be the object of a questioning lights of the leader. The answers will be determining in the choice of the type of motivation which be used to maintain the performance of the team.

How is it remunerated reached by the unit? The challenge of a leader is to be posed thousand and one question, and through the multiple answers collected, to lead its boat to good port. It is a question of understanding that the presence of change to continuous, and the installation of competitive to cope with the winds and enjoyed strategies which disturb the company, can affect considerably the effectiveness and the efficiency of the team. The performance of the team can be once upwards, another downwards in the choice of the type of motivation which will be used to maintain the performance of the team.

If this reasoning is followed, we can conclude from it that in fact the competitive strategies have a negative impact on the performance of the team, but rather the impact of the manager, leaders or managers, and their ways of managing of the team in high level efficiency.

We are convinced today that the governance is closely related to the performance of the team. What appear to us more factors of maintenance of their performance is undoubtedly the role which the collaborators within each team hold. Fall in the choice of the type of motivation has which will be used to maintain the performance of the team.

The maintenance of the performance of the teams will be possible thus thanks to a leader follower of the positive thought, which knows the advantages of the flexibility, and which remains with the mounting of any possibility for improvement. This leader understand what motivates each member of his team, visionary, it does not discourage itself easily and thus encourages, motivates and boosts its team to maintain her performance. It will give to its team to maintain her performance.

It will give to its teal the power to achieve their missions while envisaging stages of control, and by checking as its instructions are understood and accepted.

This conclusion, which we could deduce will be checked in our future article, which will follow the empirical part directly. This step will offer certainly a clearer answer to us compared to validate or not our deduction. 


\section{Conclusion}

We cannot conclude without specifying that the places of governance are burst now more, no matter what one says, and a new pragmatism is settling which is built on a direct call with the realism of the modern negotiation.

What thus generates non powerful teams with the continuous one, or pathologies of governance were these multiple rules of transparency and imputability which follow each skid. And as Daniel Innerarity (2006) affirms it, "it is rather the requirement of the calculation which would have to be replaced, by preferring that of the debate to him" (p.232). In fact, it continues by stressing that "the future will belong to those which will be able to imagine the mixed one adequately, the complex, and the articulation of heterogeneous". What thus misses they are "concepts and actions in adequacy with a complexity prohibiting to us to rest on an expert who would save to us the effort and the responsibility to treat it by the democratic procedures".

The governance is child of complexity, because she does not claim any more that the world is placid and simple, but she agrees the challenge to seek to set up mechanisms of propection and collaboration, which ensure a coordination some, and which can carry out towards a durability of the action, and thus of maintenance of the performance of the teams.

The governance cannot thus be satisfied to develop some practical useful to improve the control surface of the organizations, it must also launch out in a new process of innovation in decision making. The governance thus is the place of the mental cartography of the organization, its environment, its mission, and its projects. Its mission is to give direction and authority to the various processes by which the collective training concretized, and the organization changes, innovates, is renewed, and thus makes it possible to its teams to open out, and thus to durably maintain their performance.

\section{References}

A.G.L. Romme, (2003). Making a difference: Organization as Design" Organization Science, 14, 558.

Alberta S. (2004). The future of federalism in the European Union

Bent F. (2001) Making Social Science Matter. Cambridge: Cambridge University Press

Bob J. (2002). Governance and Meta-Governance: On Reflexivity, Requisite Variety, and Requisite Irony" The Department of Sociology, Lancaster University at www.comp.lancs.ac.uk/sociology/soc108rj.htm

Charles H. (1992). Balancing Corporate Power: A New Federalist Paper "Harvard Business Review, 70,

Daniel I. (2006). La démocratie sans l'Etat, Paris.
Donald A. Schôn, Martin Rein (1994). Frame Reflection: Toward the Resolution of Intractable Policy Controversies . New York: Basic Book.

Donald A. S. (1990). The design process" in V.A Howard, Editions Varieties of Thinking, London: Routledge, 1990, 131-132.

Don T and Anthony D. W (2006). Wikinomics. New York, Portfolio

Gerard F. (2005). The three ways of getting things done, Dorset, England: Triarchy Press.

George H. Mead, L'esprit, Le soi, La société, Paris : Presses Universitaires de France, 1963.

Gilles P and Christopher W. (2011). Collaborative coGovernance as inquiring Systems, from www.optimumonline.ca 41(2l) 2011

Gilles P. (2009). Scheming Virtuously: Te Road to Collaborative Governance, Ottawa: Invenire Books, Part IV

Gilles P. (2005). The New Geo-Governance: A Baroque Approach, Ottawa: The University of Ottawa Press.

Gilles P. (2004). Pathologies de gouvernance, Montréal : Liber.

Gilles P. (2001). Gouvernance collaborative: un antimanuel. Montréal : Liber 2011, Partie II.

Gilles P. (1991). Un pari sur les contrats moraux, Optimum.

Henri Lefebvre, " Utopie expérimentale: pour un nouvel urbanisme » Revue Française de Sociologie, 2 (3), 1961, 1916198

James O'Toole, Warren Bennis (1992). Our Federalist Future: The Leadership Imperative" California Management Review, 34, 73-90

James G. M. (2008). Explorations in organizations. Stanford: Stanford Business Books.

Jan-Peter VoB et al (2006). Reflexive Governance for Sustainable Development, Cheltenham: Edward Edgar, 4.

Jane J. (2009) Systems of Survival, New York: Random House, 1992. Yvan Allaire \& Mihaela Firsirotu, Black Markets and Business Blues, Montreal: FI Press.

Jean-Pierre G. (2002). Pourquoi la gouvernance ? Paris : Presses de Science Po, 10

Karen S. (2004) "Toward a Theory of Government" in Helen Mc Carthy et al , Network Logic, London: Demos, 45

Marco W. (2007). Efficient Organizational Design, Basingstoke, Palgrave Macmillan.

Masahiko A. (2010).Corporations in Evolving Diversity, Oxford: Oxford University Press.

Merchant, K.A (1989). Rewarding results, motivating profit center managers, Harvard Business School Press.

Merchant K. A, Stringer C et al. (2009). Theivanan thampillai , P "Relationships between Objective and Subjective Performance Ratings.

Michael H. (2008). The gridlock economy, New York: Basic Books, 2008.

Michael S. (2000). Serious play, Boston: Harvard Business School Press.

Michel M, R, Communication, Interaction et coordination des comportements, in Bernard Guilhon et al , 469.

Nadine M. (1997). Externalités, apprentissage et dynamique technologique-Retour sur la notion de réseau, in Bernard Guilhon et al, Economie de la connaissance et organisations, Paris: L'Harmattan, 349. 
Pierre-Yves G. and Harry K. (2008) Entrepreneurs and Democracy : A Political Theory of Corporate Governance. Cambridge: Cambridge University Press.

Porter, (1985) Competitive advantage: Creating and sustaining superior performance, New York: Free Press

Porter, (1980) Competitive strategy: Techniques for analyzing industries and competitors, New York: Free Press

Prahalad, C. K and Hamel, G. (1990). The core competence of the corporation, Harvard Business Review, 68, may-june, p. 79-91

Richard P. Chait et al. (2005). Governance as leadership, New York: Wiley, ch.6
Roger M. (2009). The design of business, Boston: Harvard Business Press.

Solveig W and Richard N et al. (1994). Knowledge and value, London: Routledge.

Thomas F. (2000). La dynamique de l'organisation relationnelle : conventions et réseaux sociaux au regard de l'enchevêtrement des modes de coordination » Finance Contrôle Stratégie, 111-143

Ubert S and Charles A. (2004).The Conductive Organization, Amsterdam: Elsevier.

Yochai B. (2006). The Wealth of Networks, New Haven: Yale University Press 